\title{
P14 methylation: an epigenetic signature of salivary gland mucoepidermoid carcinoma in the Serbian population
}

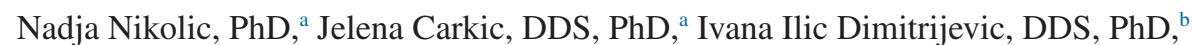
Najib Eljabo, MSc, PhD student, ${ }^{a}$ Milena Radunovic, MD, PhD, ${ }^{c}$ Boban Anicic, DDS, PhD, ${ }^{\mathrm{b}}$ Nasta Tanic, PhD, ${ }^{\mathrm{d}}$ Markus Falk, $\mathrm{PhD},{ }^{\mathrm{e}}$ and Jelena Milasin, $\mathrm{PhD}^{\mathrm{a}}$

Objective. To investigate the prevalence of $\mathrm{p} 16^{\mathrm{INK} 4} \mathrm{a}, \mathrm{p} 14^{\mathrm{ARF}}$, tumor protein $\mathrm{p} 53$ (TP53), and human telomerase reverse transcriptase (hTERT) promoter hypermethylation in mucoepidermoid carcinomas (MECs) and search for a possible association between methylation status and clinicopathological parameters.

Study design. DNA extracted from 35 formalin-fixed and paraffin-embedded MEC samples and 10 normal salivary gland (NSG) tissue samples was analyzed for the presence of promoter hypermethylation using methylation-specific polymerase chain reaction testing.

Results. The percentages of gene hypermethylation in MECs versus NSGs were the following: p14: $100 \%$ versus $20 \%(P<.001)$; p16: $60 \%$ versus $20 \%(P=.035)$; hTERT: $54.3 \%$ versus $20 \%(P=.078)$; and TP53: $31.4 \%$ versus $30 \%(P=.981)$. Multiple sites were found to be methylated in $86 \%$ of MECs compared with $10 \%$ in NSGs $(P<.001)$. TP53 and hTERT were more often methylated in lower clinical stages $(P=.033$ and $P=.005$, respectively).

Conclusions. Hypermethylation of p14 appears to be an important event in the development of mucoepidermoid carcinoma. High frequency of gene hypermethylation and high incidence of methylation at multiple sites point to the importance of epigenetic phenomena in the pathogenesis of MECs, although with modest impact on clinical parameters. (Oral Surg Oral Med Oral Pathol Oral Radiol 2018;125:52-58)

Mucoepidermoid carcinoma (MEC) accounts for approximately $35 \%$ of salivary gland cancers, ranging from nonaggressive low-grade to aggressive high-grade tumors. ${ }^{1-5}$ Several malignant and benign tumors can histologically mimic MEC, such as Warthin tumor, adenoid cystic carcinoma, and squamous cell carcinoma, among others, leading to misdiagnosis. ${ }^{6,7}$ MEC pathogenesis studies have mainly been focused on the reciprocal chromosomal translocation $\mathrm{t}(11 ; 19)(\mathrm{q} 21 ; \mathrm{p} 13)$, which gives rise to a fusion oncoprotein MECT1-MAML2. This fusion appears to be one of the drivers of MEC development through Notch signaling disruption. ${ }^{8}$ It also represents an important prognostic parameter ${ }^{9,10}$; namely, it was found that patients with MEC harboring the translocation have a less aggressive form of tumor and a more favorable outcome. ${ }^{11,12}$ Recently, using whole exome sequencing, several new alterations have been found in MECs, such

\footnotetext{
This work was financially supported by the grant \# 175075 of the Ministry of Education, Science and Technological Development of the Republic of Serbia.

a'Department of Human Genetics, School of Dental Medicine, University of Belgrade, Belgrade, Serbia.

${ }^{\mathrm{b} C l i n i c}$ for Maxillofacial Surgery, School of Dental Medicine, University of Belgrade, Belgrade, Serbia.

'Department of Microbiology, School of Dental Medicine, University of Belgrade, Belgrade, Serbia.

${ }^{\mathrm{d}}$ Laboratory for Radiobiology and Molecular Genetics, Institute of Nuclear Sciences "Vinca", University of Belgrade, Belgrade, Serbia. ${ }^{\text {e}}$ Institute of Haematopathology Hamburg, Hamburg, Germany.

Received for publication May 15, 2017; returned for revision Sep 11, 2017; accepted for publication Sep 21, 2017.

(c) 2017 Elsevier Inc. All rights reserved.

2212-4403/\$ - see front matter

https://doi.org/10.1016/j.0ooo.2017.09.013
}

as tumor protein p53 (TP53) and POU6F2 mutations. ${ }^{9}$ Still, these genetic changes cannot explain all MEC cases.

The latest molecular studies have broadened the knowledge on the importance of epigenetic changes associated with salivary gland cancer (SGC) development, in particular DNA methylation, as a mechanism of gene silencing. Kishi et al. ${ }^{13}$ found, for instance, that RB1 was hypermethylated in $42 \%$ of cases of SGC, and Nikolic et al. ${ }^{14}$ reported that approximately $70 \%$ of pleomorphic adenomas harbored hypermethylated p14 and p16. Using a microarray approach, Bell et al. ${ }^{15}$ also found several highly methylated genes in adenoid cystic carcinoma. Williams et al. ${ }^{16}$ found $48 \%$ of methylated RASSF1A in salivary duct cancers, whereas Zhang et al. ${ }^{17}$ correlated RASSF1A promoter hypermethylation with poor survival in patients with salivary adenoid cystic carcinoma in a Chinese population. In the same type of tumors, on the other hand, Tan et al. ${ }^{18}$ found that AQP1 was hypomethylated in $75 \%$ of cases.

Nonetheless, the number of published studies is still relatively limited and mostly focused on gene methylation in adenoid cystic carcinomas. Findings on DNA methylation status in mucoepidermoid carcinomas are

\section{Statement of Clinical Relevance}

Methylation of the p14 tumor suppressor gene seems to be a critical event in the pathogenesis of mucoepidermoid carcinoma and consequently p14 could be potentially used as a target in novel therapeutic approaches based on DNA epigenetic modifications. 
extremely scarce, ${ }^{13,19}$ and that fact prompted us to explore the potential role of methylation in the pathogenesis of this type of tumor. The following genes known to be implicated in the etiology of different malignancies were selected for the present study: CDKN2A or INK4 a-ARF locus, which encodes 2 tumor suppressors ( $16^{\mathrm{INK} 4 \mathrm{a}}$ and $\left.\mathrm{p} 14^{\mathrm{ARF}}\right)$, TP53, and human telomerase reverse transcriptase (hTERT). p16 is a potent cell cycle regulator, and when absent or nonfunctional, the progression of the cell cycle into the $S$ phase is enabled. ${ }^{20}$ p14 is one of the key p53 regulators; thus methylated p14 would mean inactive p53 tumor suppressor. ${ }^{21}$ The TP53 gene, the most commonly mutated gene in human cancer, encodes the p53 suppressor, which promotes cell cycle arrest or apoptosis under replication stress; epigenetic modifications affect TP53 expression and p53 function. ${ }^{22}$ The hTERT gene encodes the protein subunit of the enzyme telomerase. Telomere maintenance by telomerase has a key role in carcinogenesis, and hTERT expression is known to be the limiting step in telomerase function. ${ }^{23}$

With the aim of assessing their respective contribution to MEC development, progression, and outcome, the methylation status of 2 gene promoters analyzed in the past (p14 and p16) and 2 gene promoters not examined before (TP53 and hTERT) has been determined.

\section{MATERIALS AND METHODS}

This retrospective study included 45 formalin-fixed, paraffin-embedded samples originating from $35 \mathrm{pa}$ tients with mucoepidermoid carcinoma (surgically treated between 2000 and 2010 at the Clinic for Maxillofacial Surgery, School of Dental Medicine, University of Belgrade) and 10 controls. The control specimens were normal salivary glands (NSGs) obtained from patients with oral cancer who underwent radical neck dissection, which included the submandibular glands. Only tissue histopathologically confirmed as tumor free was used as control tissue. Initial histopathologic findings obtained from the Department of Pathology, School of Dental Medicine, University of Belgrade, were confirmed at the Institute of Hematopathology Hamburg, Hamburg, Germany. Patients with MEC with distant metastases were excluded from the study. MECT1-MAML2 translocation analysis on these cases was done in a previous study. ${ }^{11}$ Relevant clinicopathologic data are given in Table I. The research was conducted in full accordance with the World Medical Association Declaration of Helsinki (Version 2002).

The promoter methylation status was determined by methylation-specific polymerase chain reaction (PCR). An adaptation of the protocol suggested by Herman et al. ${ }^{24}$ was implemented. Genomic DNA was extracted from formalin-fixed, paraffin-embedded samples using phenolchloroform extraction and was modified by sodium bisulfite treatment with an EZ-DNA Methylation Kit,
Table I. Clinicopathologic features of patients with mucoepidermoid carcinoma (MEC) and demographic data for patients with MEC and normal salivary glands (NSG)

\begin{tabular}{llcc}
\hline Characteristic & & MECs & NSGs \\
\hline Mean age, y & & $53.03 \pm 17.53$ & $56.27 \pm 12.05$ \\
Male:female ratio & & $0.9: 1$ & $1.4: 1$ \\
Mean duration of & & $4.47 \pm 3.57$ & \\
$\quad$ disease, y & & & \\
Tumor site & Parotid & 18 & \\
& Submandibular & 6 & \\
& Sublingual & 4 & \\
& Palate & 5 & \\
Tumor size & Retromolar & 2 & \\
& $>2$ cm & 15 & \\
Positive lymph & $<2$ cm & 20 & \\
nodes & & 10 & \\
Clinical stage & I and II & 25 & \\
Perineural & III and IV & 10 & \\
invasion & & 10 & \\
\hline
\end{tabular}

according to manufacturer's recommendations (Zymo Research, Orange, CA, USA). Modified DNA was purified and resuspended in $20 \mu \mathrm{L}$ of elution buffer provided in the kit. Subsequent methylation-specific PCR was used to distinguish unmethylated alleles, based on DNA sequence alterations after bisulfite treatment of DNA. Two separate PCR reactions were performed for each gene, using primers designed for methylated and unmethylated $\mathrm{CpG}$ islands in the promoter region. Primers used in this study were reported previously ${ }^{24-27}$ and the sequences are listed in Table II. The modified genomic DNA samples were PCR amplified in a total volume of $50 \mu \mathrm{L}$, and the reaction mix contained $1 \times$ PCR buffer $(10 \mathrm{mM}$ Trishydrochloride, $50 \mathrm{mM}$ potassium chloride, $0.1 \%$ Triton $\mathrm{X}-100), 8 \mathrm{mM}$ magnesium chloride, $1.25 \mathrm{mM}$ deoxynucleoside triphosphates, $0.6 \mu \mathrm{M}$ primers (Invitrogen, Life Technologies, Carlsbad, CA, USA), $0.4 \mu \mathrm{g} / \mu \mathrm{L}$ bovine serum albumin, $5 \%$ dimethyl sulfoxide, 1.5 U Taq polymerase (Thermo Scientific, Hudson, $\mathrm{NH}$, USA), and $3 \mu \mathrm{L}$ of bisulfite-treated DNA template. Amplification was performed in a PeqStar 96 Universal thermal cycler (PEQLAB Biotechnologie $\mathrm{GmbH}$, Erlangen, Germany) under the following conditions: initial denaturation at $95^{\circ} \mathrm{C}$ for $5 \mathrm{~min}$, followed by 40 cycles $95^{\circ} \mathrm{C}$ denaturation for $30 \mathrm{~s}$, annealing for $30 \mathrm{~s}$ (primer-specific temperatures are listed in Table 2), $72^{\circ} \mathrm{C}$ extensions for $30 \mathrm{~s}$, and final extension at $72^{\circ} \mathrm{C}$ for $4 \mathrm{~min}$. Genomic DNA extracted from lymphocytes of healthy donors was used as control for unmethylated genes. The same DNA, treated in vitro with Spiroplasma sp. strain MQ1 (SssI) methyltransferase, was used as a positive control for methylated genes. PCR products were loaded on $8 \%$ polyacrylamide gels, stained with ethidium bromide, and visualized under ultraviolet light. 
Table II. Primer sequences, product lengths, and annealing temperatures

\begin{tabular}{|c|c|c|c|}
\hline Primer & Primer sequence & Length $(b p)$ & Annealing temperature \\
\hline $\mathrm{p} 14^{\mathrm{ARF}} \mathrm{U} 1$ & TTTTTGGTGTTAAAGGGTGGTGTAGT & & \\
\hline $\mathrm{p} 14^{\mathrm{ARF}} \mathrm{U} 2$ & CACAAAААСССТСАСТСАСАACAA & 132 & $53^{\circ} \mathrm{C}$ \\
\hline $\mathrm{p} 14^{\mathrm{ARF}} \mathrm{M} 1$ & GTGTTAAAGGGCGGCGTAGC & & \\
\hline $\mathrm{p} 14^{\mathrm{ARF}} \mathrm{M} 2$ & AAAACCCTCACTCGCGACGA & 122 & $53^{\circ} \mathrm{C}$ \\
\hline $\mathrm{p} 16^{\mathrm{INK} 4 \mathrm{a}} \mathrm{U} 1$ & TTATTAGAGGGTGGGGTGGATTGT & & \\
\hline $\mathrm{p} 16^{\mathrm{INK} 4 \mathrm{a}} \mathrm{U} 2$ & CAACCCCAAАCCACAACCATAA & 151 & $60^{\circ} \mathrm{C}$ \\
\hline $\mathrm{p} 16^{\mathrm{INK} 4 \mathrm{a}} \mathrm{M} 1$ & TTATTAGAGGGTGGGGCGGATCGC & & \\
\hline $\mathrm{p} 16^{\mathrm{INK} 4 \mathrm{a}} \mathrm{M} 2$ & GACCCCGAACCGCGACCGTAA & 150 & $65^{\circ} \mathrm{C}$ \\
\hline TP53 U1 & TTGGTAGGTGGATTATTTGTTT & & \\
\hline TP53 U2 & CCAATCCAAAAAAACATATCAC & 247 & $58^{\circ} \mathrm{C}$ \\
\hline TP53 M1 & TTCGGTAGGCGGATTATTTG & & \\
\hline TP53 M2 & AAATATCCCCGAAACCCAAC & 193 & $58^{\circ} \mathrm{C}$ \\
\hline hTERT U1 & TTGAGAATTTGTAAAGAGAAATGATG & & \\
\hline hTERT U2 & ACTAAAAACAAACCCAAAAACACA & 133 & $55^{\circ} \mathrm{C}$ \\
\hline hTERT M1 & TTGAGAATTTGTAAAGAGAAATGAC & & \\
\hline hTERT M2 & TAAAAACGAACCCGAAAACG & 131 & $55^{\circ} \mathrm{C}$ \\
\hline
\end{tabular}

$b p$, base pair; $h T E R T$, human telomerase reverse transcriptase; $M$, methylated sequence; $T P 53$, tumor protein p53; $U$, unmethylated sequence.

Table III. Distribution of methylated gene promoters in mucoepidermoid carcinoma (MEC) and normal salivary gland (NSG) groups

\begin{tabular}{lccccc}
\hline & & $p 16(\%)$ & $p 14(\%)$ & TP53 (\%) & hTERT (\%) \\
\hline No. of cases $(\%)$ & MEC 35 (100) & $21(60)$ & $35(100)$ & $11(31.4)$ & $19(54.3)$ \\
& NSG 10 (100) & $2(20)$ & $2(20)$ & $3(30)$ & $2(20)$ \\
$\chi^{2}$ (Fisher's exact) $P$ value & & $.035^{*}$ & $<.001^{*}$ & .931 & .078 \\
\hline
\end{tabular}

hTERT, human telomerase reverse transcriptase; TP53, tumor protein $\mathrm{p} 53$.

*Statistically significant.

The genes were considered as (1) nonmethylated, when only the reactions with the unmethylated target-specific (U) primers had amplification, and (2) methylated or partially methylated, when a positive amplification was obtained only with the methylated target-specific (M) primer pair or with both ( $\mathrm{U}$ and $\mathrm{M})$. Reamplification of $20 \%$ of randomly chosen samples was done to confirm the findings, and there were no discrepancies between methylation statuses determined in duplicate.

\section{Statistical analysis}

All statistical analyses were done using Statistical Package for Social Science (SPSS software package, Version 17.0; SPSS Inc., Chicago, IL, USA). The differences of gene methylation status between different tumor types were assessed using Pearson's $\chi^{2}$ test unless the smallest expected value was $<5$, in which case Fisher's exact test was used. $P$ value $<.05$ was considered statistically significant.

\section{RESULTS}

\section{Methylation status}

The most remarkable finding was that $100 \%$ of MECs exhibited p14 promoter hypermethylation, versus only $20 \%$ of control specimens $(P<.001)$. p16 hypermethylation was also statistically more common in
MECs than in controls ( $60 \%$ vs. $20 \%, P=.035)$. No statistically significant difference was identified for the presence of TP53 hypermethylation between MECs and NSGs (31.4\% vs. $30 \%, P=.931)$, or for the presence of hTERT hypermethylation ( $54.3 \%$ vs. $20 \%, P=.078)$. The frequencies of methylated promoter regions are summarized in Table III.

In all 35 analyzed cancer cases at least 1 of the 4 examined promoters had hypermethylation. A total of 30 $(86 \%)$ MECs exhibited simultaneous hypermethylation of 2 or more genes, versus only 1 control sample (10\%) with more than 1 methylated gene $(P<.001)$ (Table IV).

\section{Methylation status and clinical stage/histologic grade}

All MEC cases harboring TP53 hypermethylation had been classified as lower clinical stages $(P=.033)$. Similarly, hTERT hypermethylation dominated in stages I and II compared with stages III and IV $(P=.002)$. There was no association between methylation and histologic grades (Table V).

\section{Methylation status and overall survival}

Promoter methylation status did not have a statistically significant association with survival rates, although patients with methylated p16 promoter appeared to have 
Table IV. Methylation on multiple sites in mucoepidermoid carcinomas (MEC) and normal salivary glands

\begin{tabular}{lcccccr}
\hline & 1 Methylation (\%) & 2 Methylations (\%) & 3 Methylations $(\%)$ & 4 Methylations $(\%)$ & No methylations $(\%)$ & P \\
\hline MECs & $5(14.3)$ & $13(37.1)$ & $13(37.1)$ & $4(11.4)$ & $0(0)$ & $2(20)$ \\
NSGs & $7(70)$ & $1(10)$ & $0(0)$ & $0(0)$ & $<.001 *$ \\
\hline
\end{tabular}

*Statistically significant.

Table V. Distribution of methylated gene promoters in mucoepidermoid carcinomas in relation to histologic grade and clinical stage

\begin{tabular}{|c|c|c|c|c|c|c|c|}
\hline & \multicolumn{4}{|c|}{ Histologic grade } & \multicolumn{3}{|c|}{ Clinical stage } \\
\hline & $1(\%)$ & $2(\%)$ & $3(\%)$ & $P$ & $1 \& 2(\%)$ & $3 \& 4(\%)$ & $P$ \\
\hline $\mathrm{N}$ & $12(100)$ & $11(100)$ & $12(100)$ & & $26(100)$ & $9(100)$ & \\
\hline p16 & $6(50)$ & 7 (64) & $8(67)$ & .676 & $15(58)$ & $6(67)$ & .712 \\
\hline p14 & $12(100)$ & $11(100)$ & $12(100)$ & & $26(100)$ & $9(100)$ & \\
\hline TP53 & $6(50)$ & $4(36)$ & $1(8)$ & .081 & $11(42)$ & $0(0)$ & $.033 *$ \\
\hline hTERT & 7 (58) & $8(73)$ & $4(33)$ & .156 & $18(69)$ & 1 (11) & $.005^{*}$ \\
\hline
\end{tabular}

hTERT, human telomerase reverse transcriptase; $N$, number of patients per histologic grade or clinical stage; TP53, tumor protein $\mathrm{p} 53$.

*Statistically significant.

poorer survival than those with unmethylated p16. On the contrary, patients with methylated TP53 and hTERT promoter had a trend of better overall survival compared with patients with unmethylated TP53 and hTERT $(P=.120$ and $P=.151$, respectively) (Figure 1).

\section{Methylation status and MECT1-MAML2 fusion}

No correlation was found between the presence of the translocation and methylation of either of the genes $(P=.778, P=.197$, and $P=.778$ for $\mathrm{p} 16$, hTERT, and TP53, respectively).

\section{DISCUSSION}

DNA methylation, an important mechanism of gene expression regulation, is known to be involved in tumor development and progression. Indeed, it was suggested that hypermethylation is one of the main mechanisms of tumor suppressor gene (TSG) inactivation. ${ }^{28}$

Our results indicate that silencing of $\mathrm{p} 14^{\mathrm{ARF}}$, a crucial regulator of p53 activity, might be a significant event in MEC pathogenesis because this TSG was methylated in all 35 tumor samples. Although only qualitative analysis of methylation was performed, the fact that $100 \%$ of cases harbored this epimutation points to its relevance. With either hypermethylated or in any other way inactivated p14, the cell will not be able to correct damages, even with intact (wild type) p53. The present study on the importance of p14 epigenetic inactivation in the pathogenesis of MECs is in agreement with our previous findings on pleomorphic adenoma and carcinoma ex pleomorphic adenoma. ${ }^{14}$ Such a high frequency of methylation is not an uncommon phenomenon. For instance, the $\mathrm{E}$ cadherin gene was found to be hypermethylated in $95 \%$ of cutaneous squamous cell carcinomas. ${ }^{29}$ It must be emphasized that only 1 study was previously published on p14 methylation in mucoepidermoid cancer. Nishimine et al..$^{30}$ analyzed 7 cases of MEC for the presence of p14 gene alterations and found 1 deletion and no methylation at all. When considering their entire SGC sample, in which adenoid cystic carcinomas dominated, 19.4\% of methylated p14 promoter was found. ${ }^{30}$ Quite low rates for p14 methylation were found by Weber et al. $(2.5 \%)^{31}$ in pleomorphic adenomas. Ishida et al. ${ }^{32}$ reported p14 promoter hypermethylation in $20 \%$ of oral squamous cell carcinomas but found a significant association with later clinical stages and suggested that it could be a key molecular event in tumor progression.

The $\mathrm{p} 16^{\mathrm{INK} 4}$ a tumor suppressor gene encodes a cyclindependent kinase inhibitor with an important role in the cell-cycle regulation at the G1/S phase checkpoint. The absence of functional p16 protein leads to aberrant cellcycle control and promotes cancer cell proliferation. In the present study, $60 \%$ of MEC cases had p16 hypermethylation, which is fairly in line with some previous findings on the importance of this epigenetic event in salivary gland carcinogenesis, with frequencies varying between $29 \%$ and $47 \% .^{19,31,33}$ Only 2 papers analyzed p16 methylation in MECs - Guo et al. ${ }^{19}$ reported 34\% of methylated samples, whereas Nishimine et al. ${ }^{30}$ did not find any methylated p16 promoter in MECs. In accordance with our findings, Guo et al. ${ }^{19}$ indicated that the methylation rate of $\mathrm{p} 16$ in MECs increases with progression of tumor stage, but without statistical significance. Although their frequencies of p14 and p16 methylation were lower than ours (19\% and 32\%, respectively), Weber et al. ${ }^{34}$ however, concluded that the disruption of the INK4a-ARF/p53 pathway, by different mechanisms, was a very common event (84\%) in head and neck cancer squamous cell carcinomas. 

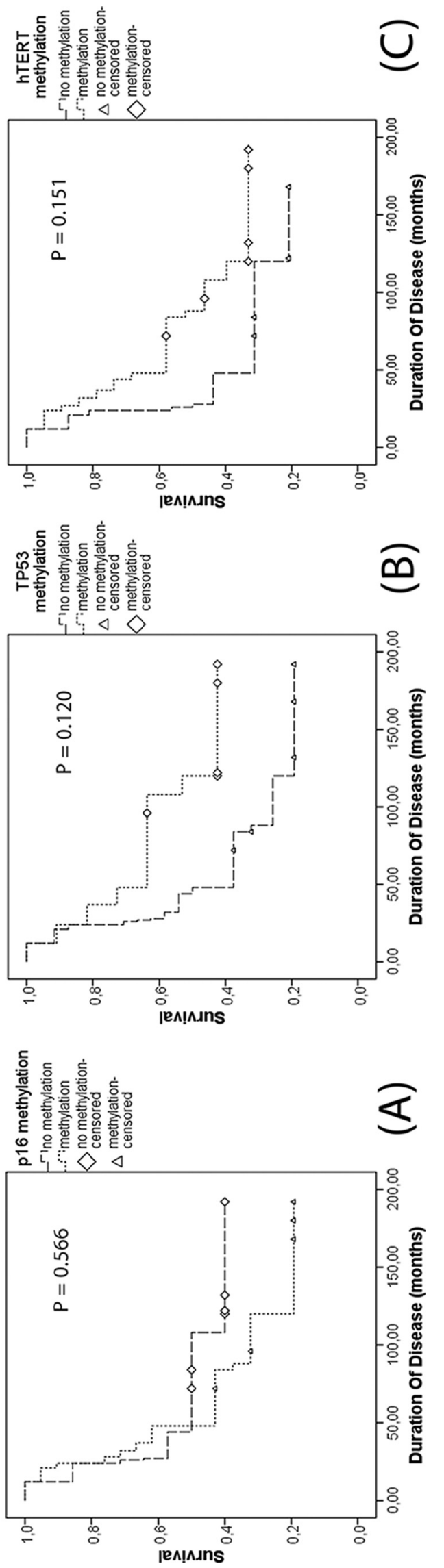

The conflicting findings related to p14 and p16 methylation frequencies may be due to different factors, such as gender, diet, stress, environment, and so on. ${ }^{35-37}$ Ethnicity is also known to greatly affect DNA methylation patterns $^{38,39}$ (and consequently gene expression). Finally, the use of detection assays with different sensitivity might in part explain the differences between the results.

Altered TP53 methylation patterns have been associated with multiple malignancies, including oral cancer. ${ }^{40}$ According to the present study, hypermethylation of TP53 is not a common event in salivary gland malignancies, and this could be a logical finding in line with high frequency of p14 methylation. Namely, infrequent methylation of TP53 does not exclude p53 from the pathogenic process but rather supports the hypothesis that p53 inactivation is preferentially achieved via p14 silencing. Some studies have found TP53 methylation in cancer tissues ${ }^{41}$ whereas others state that TP53 hypermethylation could be a normal event in healthy cells, ${ }^{40}$ which is also in agreement with our results.

One of the most important regulatory mechanisms of hTERT gene activity, and therefore of telomerase activity, is considered to be its promoter methylation, although sometimes in contrast to the general model of DNA methylation as a gene-silencing mechanism. ${ }^{42}$ Renaud et al. ${ }^{43}$ have proposed that the purpose of $\mathrm{CpG}$ island methylation in hTERT promoter is to prevent the binding of hTERT inhibitors and to allow transcription. In the present study, a statistically higher frequency of hTERT hypermethylation was found in tumors than in controls, suggesting that this molecular event might also play a role in the development of MECs. This is in accordance with some other studies that reported hypermethylation in cancerous tissue but not in normal tissue. ${ }^{44,45}$ The association of hTERT methylation with lower histologic grades and clinical stages would imply its role in the earlier phases of tumorigenesis. It also might suggest the existence of a molecular subtype of lowgrade MECs with methylated hTERT and good survival.

Generally in the present study none of the methylation events had significant association with patients' survival, which is not an infrequent situation. Although p16 methylation has been associated with poorer survival in head and neck cancer, ${ }^{46}$ results similar to ours regarding the lack of relevance of p16 and/or p14 methylation on survival have been found in oral, oropharyngeal, ${ }^{47}$ and head and neck squamous carcinomas. $^{48}$

Neoplastic cells often exhibit aberrant methylation profiles of genes involved in cell-cycle regulation, DNA repair, and/or angiogenesis. ${ }^{28} \mathrm{~A}$ so-called $\mathrm{CpG}$ island methylator phenotype was proposed by Toyota et al. ${ }^{49}$ The authors categorized all cancers into those with genome-wide methylation and those with rare methylation events. The former are more at risk of transcriptional 
silencing of numerous TSGs by promoter methylation. ${ }^{49}$ In the present study, we found that 2 or more genes were simultaneously hypermethylated in $86 \%$ of cases, which implies that hypermethylation at multiple sites might be very important in salivary gland carcinogenesis.

\section{CONCLUSIONS}

Hypermethylation of p14 appears to be a critical event in the development of mucoepidermoid carcinomas. Although in general no important association was found with clinical features, high frequency of hypermethylation of 3 of 4 studied gene promoters points to the importance of epigenetic phenomena in the pathogenesis of salivary gland neoplasms.

\section{REFERENCES}

1. Eveson JW, Auclair P, Gnepp DR, et al. Tumours of the salivary glands. In: Pathology \& Genetics Head and Neck Tumours. Lyon, France: IARC Press; 2005:209-281.

2. Johns ME, Goldsmith MM. Incidence, diagnosis, and classification of salivary gland tumors. Part 1. Oncol (Willist Park). 1989; 3:47-56.

3. Jee KJ, Persson M, Heikinheimo K, et al. Genomic profiles and CRTC1-MAML2 fusion distinguish different subtypes of mucoepidermoid carcinoma. Mod Pathol. 2013;26:213-222.

4. Fonseca FP, de Vasconcelos Carvalho M, de Almeida OP, et al. Clinicopathologic analysis of 493 cases of salivary gland tumors in a Southern Brazilian population. Oral Surg Oral Med Oral Pathol Oral Radiol. 2012;114:230-239.

5. Gong X, Xiong P, Liu S, Xu Q, Chen Y. Ultrasonographic appearances of mucoepidermoid carcinoma of the salivary glands. Oral Surg Oral Med Oral Pathol Oral Radiol. 2012;114:382387.

6. Mullin MH, Brierley DJ, Speight PM. Second opinion reporting in head and neck pathology: the pattern of referrals and impact on final diagnosis. Oral Surg Oral Med Oral Pathol Oral Radiol. 2015;119:656-660.

7. Chenevert J, Barnes LE, Chiosea SI. Mucoepidermoid carcinoma: a five-decade journey. Virchows Arch. 2011;458:133-140.

8. Tonon G, Modi S, Wu L, et al. t (11; 19)(q21; p13) translocation in mucoepidermoid carcinoma creates a novel fusion product that disrupts a Notch signaling pathway. Nat Genet. 2003;33:208213.

9. Kang H, Tan M, Bishop JA, et al. Whole-exome sequencing of salivary gland mucoepidermoid carcinoma. Am Assoc Cancer Res. 2017;23:283-288. clincanres-0720.

10. Luk PP, Selinger C, Wykes J, et al. Diagnostic and prognostic utility of mastermind-like 2 (MAML2) gene rearrangement detected by fluorescent in-situ hybridisation (Fish) in mucoepidermoid carcinoma. Pathology. 2015;47:S69.

11. Ilić Dimitrijević I, Loening T, Falk M, et al. Incidence and clinical relevance of $\mathrm{t}(11 ; 19)$ translocation in salivary gland mucoepidermoid carcinoma. Genetika. 2014;46:601-610.

12. Miyabe $S$, Okabe $M$, Nagatsuka $H$, et al. Prognostic significance of p27 Kip1, Ki-67, and CRTC1-MAML2 fusion transcript in mucoepidermoid carcinoma: a molecular and clinicopathologic study of 101 cases. J Oral Maxillofac Surg. 2009;67:1432-1441.

13. Kishi M, Nakamura M, Nishimine M, Ikuta M, Kirita T, Konishi $\mathrm{N}$. Genetic and epigenetic alteration profiles for multiple genes in salivary gland carcinomas. Oral Oncol. 2005;41:161-169.

14. Nikolic N, Anicic B, Carkic J, et al. High frequency of p16 and p14 promoter hypermethylation and marked telomere instability in salivary gland tumors. Arch Oral Biol. 2015;60: 1662-1666.

15. Bell A, Bell D, Weber RS, El-Naggar AK. CpG island methylation profiling in human salivary gland adenoid cystic carcinoma. Cancer. 2011;117:2898-2909.

16. Williams MD, Chakravarti N, Kies MS, et al. Implications of methylation patterns of cancer genes in salivary gland tumors. Clin Cancer Res. 2006;12:7353-7358.

17. Zhang C-Y, Zhao Y-X, Xia R-H, et al. RASSF1 A promoter hypermethylation is a strong biomarker of poor survival in patients with salivary adenoid cystic carcinoma in a Chinese population. PLOS ONE. 2014;9:e110159.

18. Tan M, Shao C, Bishop JA, et al. Aquaporin-1 promoter hypermethylation is associated with improved prognosis in salivary gland adenoid cystic carcinoma. Otolaryngol Neck Surg. 2014; 150:801-807.

19. Guo XL, Sun SZ, Wang WX, Wei FC, Yu HB, Ma BL. Alterations of p16 INK4 a tumour suppressor gene in mucoepidermoid carcinoma of the salivary glands. Int J Oral Maxillofac Surg. 2007; $36: 350-353$

20. Serrano M, Hannon GJ, Beach D. A new regulatory motif in cellcycle control causing specific inhibition of cyclin D/CDK4. Nature. 1993;366:704-707.

21. Eischen CM, Alt JR, Wang P. Loss of one allele of ARF rescues $\mathrm{Mdm} 2$ haploinsufficiency effects on apoptosis and lymphoma development. Oncogene. 2004;23:8931-8940.

22. Khan Z, Bisen PS. Oncoapoptotic signaling and deregulated target genes in cancers: special reference to oral cancer. Biochim Biophys Acta (BBA) Rev Cancer. 2013;1836:123-145.

23. Counter CM, Meyerson M, Eaton EN, et al. Telomerase activity is restored in human cells by ectopic expression of hTERT (hEST2), the catalytic subunit of telomerase. Oncogene. 1998;16:12171222 .

24. Herman JG, Graff JR, Myöhänen S, Nelkin BD, Baylin SB. Methylation-specific PCR: a novel PCR assay for methylation status of CpG islands. Proc Natl Acad Sci USA. 1996;93:9821-9826.

25. Klump B, Hsieh CJ, Nehls O, et al. Methylation status of p14 ARF and p16 INK4 a as detected in pancreatic secretions. Br J Cancer. 2003;88:217-222.

26. Amatya VJ, Naumann U, Weller M, Ohgaki H. TP53 promoter methylation in human gliomas. Acta Neuropathol. 2005;110:178184

27. Silva PNO, Gigek CO, Leal MF, et al. Promoter methylation analysis of SIRT3, SMARCA5, HTERT and CDH1 genes in aging and Alzheimer's disease. J Alzheimers Dis. 2008;13:173-176.

28. Esteller M, Herman JG. Cancer as an epigenetic disease: DNA methylation and chromatin alterations in human tumours. J Pathol. 2002;196:1-7.

29. Murao K, Kubo Y, Ohtani N, Hara E, Arase S. Epigenetic abnormalities in cutaneous squamous cell carcinomas: frequent inactivation of the RB1/p16 and p53 pathways. Br J Dermatol. 2006;155:999-1005.

30. Nishimine M, Nakamura M, Kishi M, et al. Alterations of p14 ARF and p16 INK4 a genes in salivary gland carcinomas. Oncol Rep. 2003; 10:555-560

31. Weber A, Langhanki L, Schütz A, Wittekind C, Bootz F, Tannapfel A. Alterations of the INK4 a-ARF gene locus in pleomorphic adenoma of the parotid gland. J Pathol. 2002;198:326334.

32. Ishida E, Nakamura M, Ikuta M, et al. Promotor hypermethylation of $\mathrm{p} 14 \mathrm{ARF}$ is a key alteration for progression of oral squamous cell carcinoma. Oral Oncol. 2005;41:614-622.

33. Li J, El-Naggar A, Mao L. Promoter methylation of p16 INK4 a, RASSF1 A, and DAPK is frequent in salivary adenoid cystic carcinoma. Cancer. 2005;104:771-776. 
34. Weber A, Bellmann U, Bootz F, Wittekind C, Tannapfel A. INK4 a-ARF alterations and p53 mutations in primary and consecutive squamous cell carcinoma of the head and neck. Virchows Arch. 2002;441:133-142.

35. Ong TP, Moreno FS, Ross SA. Targeting the epigenome with bioactive food components for cancer prevention. J Nutrigenet Nutrigenomics. 2011;4:275-292.

36. Bacalini MG, Friso S, Olivieri F, et al. Present and future of antiageing epigenetic diets. Mech Ageing Dev. 2014;136:101-115.

37. Kim K, Friso S, Choi S-W. DNA methylation, an epigenetic mechanism connecting folate to healthy embryonic development and aging. J Nutr Biochem. 2009;20:917-926.

38. Devaney JM, Wang S, Furbert-Harris P, et al. Genome-wide differentially methylated genes in prostate cancer tissues from AfricanAmerican and Caucasian men. Epigenetics. 2015;10:319-328.

39. Ambrosone CB, Young AC, Sucheston LE, et al. Genome-wide methylation patterns provide insight into differences in breast tumor biology between American women of African and European ancestry. Oncotarget. 2014;5:237-248.

40. De Oliveira SRL, Da Silva ICB, Mariz BALA, Pereira AMBC, De Oliveira NFP. DNA methylation analysis of cancer-related genes in oral epithelial cells of healthy smokers. Arch Oral Biol. 2015; 60:825-833

41. Saldaña-Meyer R, Recillas-Targa F. Transcriptional and epigenetic regulation of the p53 tumor suppressor gene. Epigenetics. 2011; 6:1068-1077.

42. Daniel M, Peek GW, Tollefsbol TO. Regulation of the human catalytic subunit of telomerase (hTERT). Gene. 2012;498:135-146.

43. Renaud S, Loukinov D, Abdullaev Z, et al. Dual role of DNA methylation inside and outside of CTCF-binding regions in the transcriptional regulation of the telomerase hTERT gene. Nucleic Acids Res. 2007;35:1245-1256.
44. Schache AG, Hall G, Woolgar JA, et al. Quantitative promoter methylation differentiates carcinoma ex pleomorphic adenoma from pleomorphic salivary adenoma. Br J Cancer. 2010;103:18461851.

45. Wang Z, Xu J, Geng X, Zhang W. Analysis of DNA methylation status of the promoter of human telomerase reverse transcriptase in gastric carcinogenesis. Arch Med Res. 2010;41:1-6.

46. Roh J-L, Wang XV, Manola J, Sidransky D, Forastiere AA, Koch WM. Clinical correlates of promoter hypermethylation of four target genes in head and neck cancer: a cooperative group correlative study. Clin Cancer Res. 2013;19:2528-2540.

47. Al-Kaabi A, Van Bockel LW, Pothen AJ, Willems SM. p16 INK4 A and p14 ARF gene promoter hypermethylation as prognostic biomarker in oral and oropharyngeal squamous cell carcinoma: a review. Dis Markers. 2014;2014:260549.

48. Virani S, Bellile E, Bradford CR, et al. NDN and CD1 A are novel prognostic methylation markers in patients with head and neck squamous carcinomas. BMC Cancer. 2015;15:825.

49. Toyota M, Ahuja N, Ohe-Toyota M, Herman JG, Baylin SB, Issa J-PJ. CpG island methylator phenotype in colorectal cancer. Proc Natl Acad Sci USA. 1999;96:8681-8686.

\section{Reprint requests:}

Jelena Milasin, $\mathrm{PhD}$

Department of Human Genetics

School of Dental Medicine

University of Belgrade

Dr Subotica 8, 11000 Belgrade

Serbia

jelena.milasin@stomf.bg.ac.rs 